\title{
Controlling Wheat Gluten Cross-Linking for High Temperature Processing
}

\author{
Thomas LANGSTRAAT ${ }^{a,{ }^{*}}$, Koen JANSENS ${ }^{b}$, Jan DELCOUR ${ }^{b}$, Bart GODERIS $^{a}$ \\ ${ }^{a}$ Polymer Chemistry and Materials Division, Department of Chemistry, KULeuven, Celestijnenlaan 200F, 3001 Leuven, Belgium. \\ ${ }^{b}$ Laboratory of Food Chemistry and Biochemistry, KULeuven, Kasteelpark Arenberg 20, 3001 Leuven, Belgium. \\ *Corresponding author: thomas.langstraat@chem.kuleuven.be
}

\begin{abstract}
The high temperature blending of wheat gluten with other components for the manufacturing of bioplastics is somewhat limited by heat induced cross-linking reactions. In this work it was shown that a good level of control can be obtained over the onset of cross-linking during heating by adjusting the $\mathrm{pH}$ of the environment. Gluten was heated $\left(>100{ }^{\circ} \mathrm{C}\right)$ in buffer solutions of increasing acidity and protein polymerisation was followed by various methods to assess the extent and nature of aggregation. In a sufficiently acidic environment $(<p H 3)$ cross-linking was found to be greatly hindered whilst protein degradation was not observed.
\end{abstract}

\section{Introduction}

Wheat gluten (WG) is a heterogeneous mixture of gliadin and glutenin proteins which play a vital structural role in many staple food products such as bread and pasta. Various characteristics such as excellent gas barrier properties and high strength also make it an attractive candidate for the design of 'green' polymeric materials [1]. WG can be processed towards a plastic material by the application of heat and pressure to give a crosslinked structural network. This can be done both with the addition of plasticiser to give a rubbery material, or in the absence of plasticiser in which case a rigid material results [2].

A major drawback towards mainstream production of WG based plastics is its narrow window of processability. Cross-linking via a disulphide interchange mechanism [3] occurs from around $90{ }^{\circ} \mathrm{C}$ and this limits processing methods and the ability to be able to mix with other polymers. Protein degradation is also a problematic factor at high temperatures as this leads to inferior mechanical properties and so should be avoided [4]. In this work we have assessed structural changes occurring in WG during high temperature heat treatment in buffer solutions of various $\mathrm{pH}$. Acidic conditions are known to hinder protein crosslinking and this may be beneficial for industrial style processing.

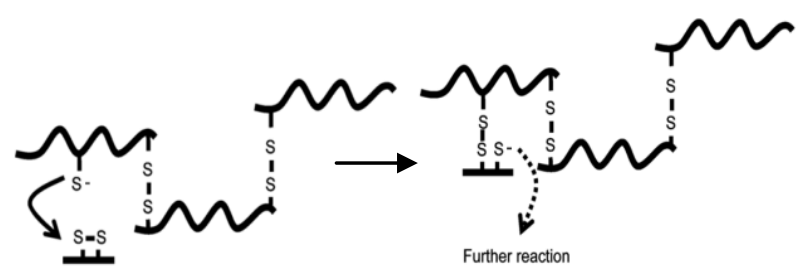

Fig. 1. Disulphide interchange reaction between monomeric gliadin and polymeric glutenin proteins.

\section{Experimental}

WG was suspended in buffer solutions ranging from $\mathrm{pH} 7-2.5$ and subsequently heated in sealed tubes to temperatures between $108-153{ }^{\circ} \mathrm{C}$. The extent to which the WG underwent cross-linking reactions during the heat treatment was assessed by protein extractability in a sodium dodecyl sulphate (SDS) solution. The chemical nature of the observed cross-linking was also characterised by various techniques.

\section{Results}

After heating at neutral $\mathrm{pH}\left(133{ }^{\circ} \mathrm{C}, 5 \mathrm{~min}\right)$ the SDS extractable proteins were reduced considerably from $88 \%$ for an untreated reference sample to $\sim 20 \%$. Further analysis showed both cross-links arising from $\beta$-elimination product dehydroalanine as well as disulphide bonds were formed. Lowering $\mathrm{pH}$ to below $\mathrm{pH} 5$ was found to supress crosslinking reactions and this effect became more pronounced with a more acidic environment. When 
heating at $\mathrm{pH} 3$ or lower almost no cross-links of any type were identified.

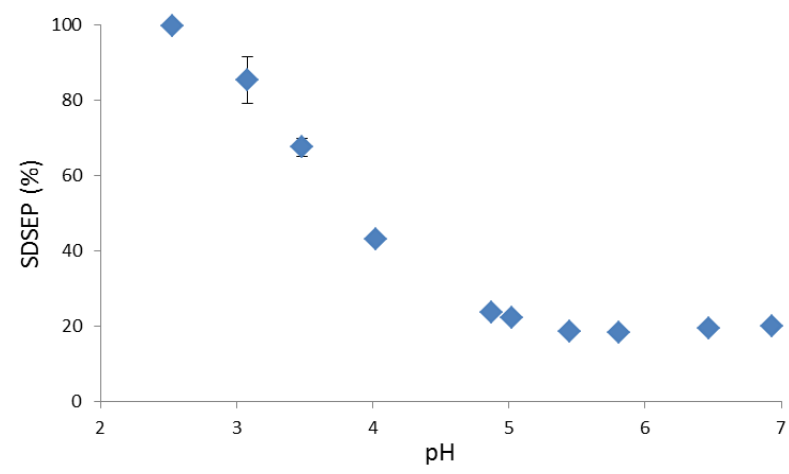

Fig. 2. SDS extractable proteins after hydrothermal treatment $\left(133{ }^{\circ} \mathrm{C}, 15 \mathrm{~min}\right)$ at different $\mathrm{pH}$.

Protein degradation via chain hydrolysis was considered by following the evolution of primary amino groups. The results suggested that degradation was very limited within the first 15 minutes of heating up to $153{ }^{\circ} \mathrm{C}$. Heating for extended periods (>30 $\mathrm{min}$ ) led to noticable degradation.

\section{Conclusions}

At low $\mathrm{pH}$ WG proved remarkably resilient against heat treatment. Protein extractability and amino acid analysis suggested that little chemical change occurred at $\mathrm{pH} 2.5$ when heating up to $153{ }^{\circ} \mathrm{C}$ and the native gliadin and glutenin structures remained largely intact. This result suggests that the use of low $\mathrm{pH}$ may be useful in facilitating high temperature processing of WG which has previously been avoided.

\section{Acknowledgments}

We would like to acknowledge the Agency for Innovation through Science and Technology Flanders (IWT Vlaanderen) for funding.

\section{References}

1. B. Lagrain, B. Goderis, K. Brijs, J. A. Delcour, Biomacromolecules, 11, 533, (2010).

2. D. L. Woerdeman, W. S. Veraverbeke, R. S. Parnas, D. Johnson, J. A. Delcour, I. Verpoest, C. J. G. Plummer, Biomacromolecules, 5, 1262, (2004).

3. J. D. Schofield, R. C. Bottomley, M. F. Timms, M. R. Booth, J. Cereal Sci., 1, 241, (1983).
4. M. Pommet, M. H. Morel, A. Redl, S. Guilbert, Polymer, 45, 6853, (2004). 